\title{
Sujeito em terceiro plano: Uma reflexão crítica acerca da articulação entre a dinâmica da terceirização e processos de subjetivação
}

Sergio Dias Guimarães Junior ${ }^{1}$, João Batista de Oliveira Ferreira

Universidade Federal do Rio de Janeiro, Rio de Janeiro, Brasil

Palavras-chave:

terceirização;

psicodinâmica do trabalho;

precarização do trabalho.

\begin{abstract}
Resumo
Neste artigo procuramos promover uma reflexão crítica acerca da articulação entre a dinâmica da terceirização e processos de subjetivação. Para tal, apresentamos os resultados qualitativos de uma pesquisa que tinha como objetivo principal analisar o trabalho de sujeitos com vínculo contratual terceirizado em uma universidade pública brasileira. À luz das contribuições teórico-metodológicas da psicodinâmica do trabalho, os resultados, aqui apresentados sob a forma de feixes de análise, apontam a predominância de formas instituídas de trabalho que tendem a abafar a capacidade inventiva dos sujeitos, revelando a multifatorialidade do processo de instrumentalização do seu fazer, conduzindo-os a horizontes de sofrimento e não criação. Em paralelo, observou-se que os primeiros passos da solução construída por esses trabalhadores e trabalhadoras diante desse cenário adverso são fecundados no solo fértil das ações coletivas, representando formas de resistência para afirmação de sua dignidade e garantia de direitos.
\end{abstract}

Subject in the background: A critical reflection on the connection between the outsourcing dynamic and processes of subjectivation

\begin{abstract}
In this article we seek to promote a critical reflection about the connection between the outsourcing dynamic and processes of subjectivation. In this regard, we present the qualitative results of research aimed at analyzing the work of outsourced workers in a Brazilian public university. In light of the theoretical-methodological contributions of the Psychodynamics of Work, the results, presented here in the form of bundles of analysis, point to the predominance of instituted forms of work that tend to stifle the inventive capacity of the subjects, revealing the multifactoriality of the process of instrumentalization of their work, leading them to horizons of suffering and non-creation. In parallel, it was observed that the first steps of the solution constructed by these workers, in view of this adverse scenario, are created in the fertile ground of collective actions, representing forms of resistance to affirm their dignity and guarantee their rights.
\end{abstract}

Sujeto en tercer plan: una reflexión crítica sobre la articulación entre la dinámica de externalización y procesos de subjetivación

\footnotetext{
Palabras-clave:

externalización;

psicodinámica del trabajo;

precariedad del trabajo.
}

\begin{abstract}
Resumen
En este artículo se pretende promover una reflexión crítica sobre la articulación entre la dinámica de externalización y procesos de subjetivación. Para ello, se presentan los resultados cualitativos de una investigación que tenía como objetivo principal analizar la labor de trabajadores subcontratados en una universidad pública brasileña. A la luz de las contribuciones teórico-metodológicas de la Psicodinámica del Trabajo, los resultados, aquí presentados bajo la forma de haces de análisis, apuntan a la predominancia de formas instituidas de trabajo que tienden a sofocar la capacidad inventiva de los sujetos, revelando la multifactorialidad del proceso de instrumentalización de su quehacer, conduciéndolos a horizontes de sufrimiento y de no creación. En paralelo, se observó que los primeros pasos de la solución construida por esos trabajadores y trabajadoras ante este escenario adverso son fecundados en el suelo fértil de las acciones colectivas, representando formas de resistencia para la afirmación de su dignidad y garantía de derechos.
\end{abstract}

\footnotetext{
Endereço para correspondência:

Universidade Federal do Rio de Janeiro, Programa de Pós-Graduação em Psicologia, 21941-901, Rio de Janeiro, RJ - Brasil. E-mail: sergiodiasguima@gmail.com Como citar este artigo:

Guimarães Junior, S. D., \& Ferreira, J. B. (2018). Sujeito em terceiro plano: Uma reflexão crítica acerca da articulação entre a dinâmica da terceirização e processos de subjetivação. Revista Psicologia: Organizações e Trabalho, 18(2), 381-389. doi: 10.17652/rpot/2018.2.14177
} 
De acordo com Antunes e Druck (2015), a terceirização é o fio condutor da precarização do trabalho no Brasil. Nessa conjuntura, este artigo representa a materialização dos resultados qualitativos de uma pesquisa realizada durante três anos - 2014, 2015 e 2016 - com funcionários e funcionárias com vínculo contratual terceirizado na Universidade Federal do Rio de Janeiro (UFRJ). O principal objetivo desse estudo foi analisar o trabalho de sujeitos envolvidos no processo de terceirização e seus desdobramentos subjetivos.

O principal referencial teórico-metodológico escolhido foi a psicodinâmica do trabalho, visto que suas formulações teóricas e práticas representam importantes ferramentas para o estudo das relações dinâmicas entre organização do trabalho e processos de subjetivação, ou seja, processos de produção de sentido, de modos de viver, de sentir, de pensar, de significar e de agir (Mendes, 2007). Partindo de tal perspectiva, a observação das vivências de prazer e sofrimento nas mais distintas situações de trabalho se faz possível.

A concepção de trabalho aqui utilizada - conceito-chave desta pesquisa - foi introduzida por Christophe Dejours como algo que implica, do ponto de vista humano, o fato de trabalhar. Nesse sentido, este "trabalhar" é a mobilização de gestos, do saber-fazer, do engajamento do corpo, da inteligência, da capacidade de refletir, de interpretar e de reagir às situações. Em outras palavras, pode-se afirmar que trabalhar representa o "poder de sentir, de pensar e de inventar" (Dejours, 2004, p. 28). É a partir dessa noção de trabalho que serão empreendidas todas as nossas análises e reflexões referentes à temática da terceirização.

O empuxo para a realização do estudo se deu, entre outros fatores, pela escassez de pesquisas relacionadas à temática da terceirização com o referencial teórico-metodológico da psicodinâmica do trabalho. Acredita-se que produções acadêmicas relacionadas à temática da terceirização se fazem cada vez mais necessárias pelo fato de que há, progressivamente, uma tendência preponderante - revelada por aprovações de projetos de lei e outras decisões políticas - que poderá culminar no que podemos chamar de um quadro de precarização generalizada das condições e relações nos contextos de trabalho.

Tendo em vista o que foi dito, este artigo está estruturado da seguinte maneira: inicialmente, será proposta uma reflexão sobre o próprio processo de terceirização e seus desdobramentos no contexto brasileiro atual; em seguida, serão apresentados os resultados da pesquisa realizada com os subcontratados da universidade, seus atravessamentos e principais articulações com o referencial teórico-metodológico escolhido.

Cabe destacar que o projeto de pesquisa em questão foi aprovado pelo Comitê de Ética em Pesquisa da Universidade Federal do Rio de Janeiro (CAAE: 55723216.9.0000.5582; Parecer: 1.625.615), vinculado ao Comitê Nacional de Ética em Pesquisa do Ministério da Saúde do Brasil, quanto aos seus aspectos éticos e legais.

\section{Desdobramentos da dinâmica subcontratual}

A pragmática da acumulação flexível de capital, combinada com preceitos do capitalismo financeiro e com os ideias neoliberais, possibilitou um processo de reestruturação produtiva que culminou na ampliação da flexibilização do trabalho, da informalidade e da precarização das condições laborais no Brasil (Antunes, 2014).

De acordo com Druck (2013), o fenômeno da precarização social do trabalho capilariza-se por diferentes âmbitos da conjuntura laboral e reflete-se nas formas de organização e gestão do trabalho, nas formulações e decisões da legislação trabalhista e social, na função do Estado e na maneira como o movimento sindical revela-se no contexto contemporâneo. Dada a institucionalização desse cenário de flexibilização, instabilidade (de vínculos e relações) e vulnerabilidade de massa, observa-se uma curva ascendente do processo de fragmentação das instâncias coletivas de trabalho e da concorrência generalizada, o que tende a ser disfarçado, frequente e estrategicamente, pelas forças que defendem a chamada "fatalidade econômica", ou seja, a ideia de que a precarização das formas de trabalho é algo natural e deve ser compreendida como parte integrante e fundamental de um ansiado desenvolvimento econômico.

No bojo dessas reflexões, Dejours (1999) afirma que os principais efeitos do processo de precarização relacionam-se a: mecanismos de intensificação do trabalho, com consequente aumento do sofrimento dos sujeitos; enfraquecimento de ações e movimentos coletivos contra a dominação e sofrimento no trabalho; estratégias defensivas de sujeitos que se veem "negando o sofrimento alheio e calando o seu" (Dejours, 1999, p. 51); e crescimento do individualismo, devido, de forma particular, à constante ameaça de demissão presente nesses contextos.

Nesse terreno, formas flexíveis e informais de trabalho encontraram adubo para sua germinação, crescimento e reprodução. Com isso, a terceirização destaca-se pela sua grande eficácia frente às encomendas do capital. Particularmente, o processo de terceirização, segundo relatório da CUT-Dieese (2014), caracteriza-se por uma dinâmica na qual uma empresa contratante, ou "empresamãe", transfere a execução de uma atividade que seria realizada por um trabalhador diretamente contratado para outro trabaIhador, vinculado a uma empresa terceira ou contratada. No que tange à etimologia do termo, a ideia da palavra terceirização difere um pouco do sentido da sua equivalente em inglês outsourcing. A palavra em português remete, em nossa cultura, à ideia de algo proveniente de um terceiro, ou seja, um trabalho realizado por terceiros (por outros), enquanto o sentido literal do termo em inglês refere-se a um fornecimento vindo de fora.

A regulamentação da terceirização das atividades no Brasil, segundo o levantamento de Antunes e Druck (2015), iniciou-se na década de 1970, com as leis 6.019/74 e 5645/70. No cenário atual, observamos a temerária expansão desse processo que, de maneira preocupante, materializa-se na recente aprovação da lei 13.429/172 e nas alterações presentes na reforma trabalhista arquitetada pelo atual governo. O projeto de lei mencionado traz consigo um conteúdo que altera a legislação do trabalho temporário no Brasil e regulamenta a terceirização das atividades no país. Com ele, a subcontratação torna-se irrestrita, ou seja, todas as atividades - fim e meio - de uma organização poderão ser terceirizadas, o que representaria um processo de terceirização sem limites no país.

Importantes contribuições da sociologia do trabalho afirmam que o fenômeno da terceirização representa a principal forma de flexibilização e precarização do trabalho na conjuntura social contemporânea (Druck, 2013). Partindo dessa perspectiva, e considerando outras formas de trabalho flexível como a chamada quarteirização e a pejotização, podemos pensar sobre o modo como este fio possibilita a elaboração de tecidos sociais precários e contribui, igualmente, para que novas costuras sejam feitas no âmbito trabalhista, trazendo sérias conseqüências para os trabalhadores e trabalhadoras nele envolvidos.

À guisa de maior clareza no entendimento dessas influências, podemos observar as contribuições de alguns autores dentro desta temática: um importante relatório da CUT-Dieese (2014) e um estudo realizado por Filgueiras e Cavalcante (2015) apontam para

\footnotetext{
O conteúdo do projeto de lei em questão pode ser acessado no endereço virtual do Diário da União: http://www.planalto.gov.br/ccivil_03/_ato2015-2018/2017/ lei/L13429.htm
} 
a grande discrepância salarial entre subcontratados e funcionários diretos; esse mesmo relatório evidencia a alta rotatividade dos sujeitos subcontratados no cenário econômico brasileiro; Filgueiras e Dutra (2014), ao observarem o setor de call centers, revelam como os subcontratados cumprem jornadas de trabalho muito longas; Barros e Mendes (2003), ao realizarem uma pesquisa com subcontratados do setor de construção civil, confirmaram a hipótese de que os modelos de produção flexíveis, majoritários nesse contexto, potencializam o sofrimento dos trabalhadores; um relatório da Fundação Coge (2013) acerca dos empregados do setor de eletricidade no Brasil constatou que os trabalhadores e trabalhadoras subcontratados morrem 3,4 vezes mais que outros, uma vez que são alocados na realização das tarefas mais perigosas; Filgueiras (2014) reflete sobre a relação entre a terceirização e o trabalho análogo à escravidão no país; Figueiras e Druck (2014) e Lima (2010) comentam em suas publicações como práticas discriminatórias estão presentes cotidianamente na dinâmica laboral desses sujeitos.

\section{Apontamentos de pesquisa: sujeitos envolvidos e campo de trabalho}

A pesquisa em questão foi realizada com uma amostra de seis sujeitos, quatro mulheres e dois homens, todos com vínculo contratual terceirizado que prestavam serviços para a Universidade Federal do Rio de Janeiro (UFRJ). Os sujeitos envolvidos tinham idade entre 30 e 50 anos, ensino médio completo e um período mínimo de três anos de trabalho na instituição, alocados em dois de seus principais centros e unidades internas. Todos faziam parte dos setores de limpeza e almoxarifado, exercendo os cargos de auxiliar de serviços gerais ou almoxarife. As intervenções metodológicas aconteceram durante o segundo semestre de 2015, no próprio local de trabalho dos subcontratados. Os participantes que contribuíram com o estudo assinaram um Termo de Consentimento Livre e Esclarecido no qual estava expresso o caráter voluntário e anônimo da pesquisa.

Diante da realidade dos funcionários da universidade - marcada por greves e paralisações - e das (im)possibilidades de aplicação metodológica com os subcontratados durante o seu expediente de trabalho no referido período, optamos por realizar nossas entrevistas com os sujeitos alocados em duas unidades específicas da instituição, nas quais ainda era possível encontrar participantes para a pesquisa. Tais greves foram mobilizadas, principalmente, em função de atrasos salariais e do não cumprimento de obrigações trabalhistas por parte das empresas terceirizadas às quais os subcontratados estavam vinculados.

Foram realizadas entrevistas semiestruturadas com base no referencial teórico-metodológico da psicodinâmica do trabalho. Realizadas individualmente e com duração de uma hora a uma hora e meia, as entrevistas tiveram todo o seu conteúdo verbalizado transcrito e posteriormente analisado por dois pesquisadores (autores deste artigo). Para a análise das sinalizações obtidas foi escolhido o método de análise de núcleos de sentido (ANS), desenvolvido por Mendes (2007). Esse método revela-se como uma adaptação da técnica de análise de conteúdo por categorias desenvolvida por Bardin nos anos 1970. Nele, a recorrência dos temas oriundos das entrevistas representou o principal critério para a formação de categorias e núcleos de sentido baseados nas verbalizações dos sujeitos da amostra.

Cabe ressaltar que todo o processo de análise das entrevistas contou com o auxílio de um juiz para validação interna. Com graduação completa em psicologia e mestrado em andamento em psicologia social e do trabalho (tendo a psicodinâmica como um dos seus principais referenciais de pesquisa), esse indivíduo realizou uma leitura geral de cada entrevista transcrita, desdobrando o texto em unidades (possíveis núcleos de sentido) que foram formadas a partir de temas semelhantes e sobressalentes presentes nas verbalizações dos sujeitos entrevistados. Na categorização e definição final dos núcleos de sentido foram examinadas paralelamente as contribuições do juiz e o trabalho feito pelos pesquisadores, a fim de evitar qualquer tipo de viés por parte dos que efetivamente realizaram as entrevistas.

Ainda de acordo com Mendes (2007), entendemos que os objetivos da entrevista em psicodinâmica são, fundamentalmente, compreender mais detalhadamente os sentimentos, atitudes e valores em relação aos comportamentos das pessoas em contextos sociais específicos. Assim, ao agrupar o conteúdo da entrevista em núcleos de sentido, agrupa-se também o conteúdo latente e manifesto do texto, dando suporte às interpretações e inferências, e favorecendo a investigação do conteúdo psicológico subjacente às verbalizações.

\section{Feixes de análise: reflexões prático-teóricas}

Os resultados da pesquisa realizada serão apresentados a partir de uma entrada específica que denominamos de feixes de análise. Esse dispositivo de reflexão será constituído por falas e verbalizações dos sujeitos participantes da pesquisa, apresentados aqui por meio de nomes fictícios para que seja preservado seu anonimato.

De maneira geral, consideramos três feixes de análise: 1) A cadência dos instituídos e as (im)possibilidades do fazer; 2) A instituição dos instituídos e a naturalização de processos mortificantes; e 3) Fissuras que apontam para outros horizontes. Discutiremos, em seguida, cada um deles e suas sinalizações em articulação com algumas contribuições da psicodinâmica, fornecendo material para uma reflexão crítica sobre as situações de trabalho e os efeitos subjetivos para os sujeitos entrevistados.

\section{Feixe 1: A cadência dos instituídos e as (im)possibilidades do fazer}

"Perdoai, mas eu preciso ser Outros. Eu penso em renovar o homem usando borboletas" (Barros, 1998, p. 79). Considerando as palavras de Manoel de Barros, podemos observar que os conteúdos que constituem este feixe de análise possuem vetores que se relacionam, principalmente, às prescrições, às atividades e regras rotineiras e aos aspectos que se apresentam como elementos instituídos na organização do trabalho dos sujeitos entrevistados, causando-Ihes consequências negativas e, muitas vezes, impossibilitando o seu fazer. Nessa perspectiva, as sinalizações deste feixe contribuem para colocarmos em tensionamento alguns conceitos relevantes da psicodinâmica.

Nesse movimento, de acordo com Dejours (2004), devemos considerar que o real do trabalho sempre se manifesta afetivamente ao sujeito, pela sua resistência aos procedimentos. Essa ideia nos remete diretamente ao cerne da noção de trabalho que, ainda segundo este autor, é o que o sujeito adiciona ao que está instituído, prescrito, para atingir seus objetivos em suas atividades. Assim, frente a essas prescrições, o trabalho real se apresenta como algo que escapa, desvia, escorrega, desliza e foge de tais orientações. Trabalhar, portanto, seria "preencher a lacuna entre o prescrito e o real" do trabalho (Dejours, 2004, p. 28).

O conjunto de regras e manuais que deve servir de base para que a dinâmica produtiva de uma organização possa se manter perene pode, no limite, impossibilitar a ocorrência do próprio trabalhar. Em outras palavras, podemos afirmar que a fixação das formas de trabalho prescrito, por não possibilitar meios de criação 
e invenção, pode conduzir a uma cristalização e instrumentalização da capacidade de criar e inventar e, portanto, de trabalhar.

Essa reflexão permite uma articulação com o que Ferreira (2014) chamou de trabalho vivo, ao entender que o real do trabalho apresenta uma condição prolixa que resiste ao chamado campo das forças instituídas e simultaneamente institui um "não lugar" e um "tempo singular" nessa dinâmica. O real, aqui, revela-se como a principal força do que o autor considera o campo aberto das forças de ruptura, resistindo às práticas de dominação e abrindo passagem para fissuras que permitam outras possibilidades. Em suas contribuições, Ferreira apresenta o trabalho vivo como o poder de sentir, de inventar, de pensar e de mobilizar-se subjetiva e coletivamente. Por outro lado, ele define como trabalho morto todo o movimento de subtração da capacidade inventiva das pessoas, num processo semelhante à morte em vida.

Nesse sentido, como seria possível o trabalho vivo manter-se como força constituinte e viva em meio à complexidade reguladora do contexto trabalhista atual? Para essa reflexão, Ferreira, Martins e Vieira (2016) trazem importantes contribuições acerca da potência do trabalho vivo, fundamentada na experiência intempestiva do real, como ação instituinte de formas de vida ${ }^{3}$ ética e politicamente referenciadas. As proposições desses autores nos fazem refletir acerca do poder constituinte do trabalho vivo frente aos campos normativos que teimam em negar o real do trabalho e regular a vida, conduzindo os sujeitos à opacidade de processos mortificantes de viver e trabalhar.

O aluno, até pra ele se reportar com o funcionário é de uma forma, com o terceirizado é de outra forma [...]. Nós recebemos um salário mínimo, e nesse salário mínimo nós ainda temos desconto, pô, é um absurdo... então a escravidão, ela não acabou, ela continua, ela só se modernizou... (Renan - participante da pesquisa)

Ao longo das entrevistas percebemos que a condição de subcontratado atrela-se a uma roupagem de invisibilidade, a uma não presença no cotidiano das relações de trabalho. Uma espécie de mecanismo no qual um sujeito subcontratado, quando diante de um trabalhador com vínculo direto, vê-se como se estivesse refletido às avessas, ou seja, enxerga a sua imagem ao contrário no que tange às suas condições de trabalho, ao recebimento de seus direitos e ao tratamento entre pares. Como se pudesse se enxergar por meio de um espelho invertido que o reduzisse a um grau oposto ao que é visto. Em outras palavras, há uma grande discrepância entre ambos - subcontratado e contratado direto - que emerge fundamentalmente de suas condições contratuais de trabalho. Tal defasagem, em seus aspectos mais tangíveis, pode ser observada por meio do relato exposto anteriormente.

Como já mencionamos, entende-se que se o prescrito for seguido rigidamente não haverá trabalho na forma como a psicodinâmica o concebe. Pujol (2015) afirma que a força criativa que insurge nas situações de trabalho exige que o sujeito supere as técnicas e a rotina, para que este excesso as renove. $O$ trabalho criativo, nesse sentido, caminha na contramão de uma mera obediência e repetição às prescrições técnicas e normativas.

O fato de os subcontratados realizarem por iniciativa própria atividades que não estavam previamente designadas aos seus cargos e funções traz luz aos modos pelos quais os sujeitos adicionam elementos às prescrições categorizadas com a intenção de introduzir

\footnotetext{
Na reflexão apresentada, o termo "formas de vida» refere-se ao que o filósofo italiano Giorgio Agamben considera uma vida ética e politicamente qualificada, ou seja, o que está para além de uma simples sobrevivência e dos seus aspectos puramente biológicos (sobrevida).
}

um pouco de si em suas atividades. Ao incluírem nessa dinâmica os seus modos de sentir, pensar e inventar, esses sujeitos passam a mobilizar-se subjetivamente rumo a um horizonte distante das formas alienadas de subjetivação - que induzem à manutenção dos modos instituídos e identitários de trabalho e vida -, deixando furos, escapes e brechas para ações instituintes que os conduzam a destinos previamente impensados, imprevistos, desconhecidos e arriscados.

Às vezes, eu até mesmo estava fazendo trabalho de porteiro (risos), até porque agora não tem porteiro... É por isso que eu acho que a faculdade, ela tinha que ter um olhar melhor pra gente, entendeu? (Ana Paula - participante da pesquisa)

Nós estávamos fazendo roda de conversa, e essa roda de conversa era algo que eu gostaria que voltasse a ter porque era sobre terceirização [...]. Foi uma coisa muito boa porque aí nos abraçou os professores, nos abraçou os alunos. (Letícia - participante da pesquisa)

Eu tenho uma superintendência, aí depois [...] tem que ter algum chefe, esse chefe divide entre chefe de setor [...] e fiscal de contrato. Então você deve obediência a vários chefes ao mesmo tempo. (Renan - participante da pesquisa)

Outro importante aspecto da organização do trabalho dos subcontratados é a falta de referência no que tange à figura clara de uma chefia. Num emaranhado de cargos e funções entrelaçados, os subcontratados, muitas vezes, veem-se perdidos e sem referencial de pares de trabalho ou de chefia direta, o que condiciona ainda mais o seu cotidiano de trabalho a uma realidade fragmentada. Essa visão turva gera um constante sentimento de vigilância, uma sensação de estar sendo observado e até mesmo de perseguição, uma vez que não se sabe quem está efetivamente observando o fazer desses trabalhadores e trabalhadoras.

O caráter de fragmentação observado na realidade dos subcontratados a partir das entrevistas realizadas permeia outros âmbitos do cotidiano desses sujeitos e, assim, também pode ser considerado um obstáculo para a formação de um dos aspectos mais relevantes nas relações laborais: os coletivos de trabalho.

De acordo com Dejours (2012), as noções de coordenação e cooperação refletem diferentes fenômenos recorrentes nas situações de trabalho e estão intimamente relacionadas à formação de coletivos. Enquanto a primeira diz respeito às prescrições trabalhistas e ao modo como o trabalho se vê prescritivamente organizado, a segunda refere-se ao que se entende por trabalho coletivo efetivo. Se enxergarmos a realidade dos subcontratados pesquisados através dessa lente, podemos constatar que esses sujeitos se veem impedidos de conversar sobre seu fazer, de expor suas frustrações e prazeres e, principalmente, de tornar o seu trabalho visível para que possam ser retribuídos - simbólica ou materialmente - pelas suas atividades. Em suma, podemos considerar que a organização do trabalho observada se apresenta como um obstáculo para a formação de coletivos e espaços de compartilhamento.

Dejours (2004) afirma que trabalhar é viver junto. A cooperação nas situações de trabalho é atrelada à confiança e à solidariedade entre os sujeitos que partilham desse trabalhar. Assim, a cooperação viva e efetiva no trabalho é fundada na deliberação coletiva, ou seja, num processo no qual os sujeitos compreendem a particularidade das inteligências individuais de seus pares e, ao formarem coletivamente suas regras e normas de trabalho, levam em conta as preferências de todos, chegando a um consenso sobre o seu fazer e o que deve se tornar prescrito (Dejours, 2012). 
Entendemos que trabalhar pressupõe riscos. Assim, a formação de coletivos no trabalho também representa riscos para a organização vigente. Não seria um fator "estratégico" para as instituições se os trabalhadores e trabalhadoras tivessem abertura e espaços disponíveis para poderem revelar-se uns aos outros em seus contextos de trabalho, ou seja, contar sobre seus fazeres, compartilhar angústias, impasses, feitos dos quais se orgulham, reclamações, criar regras e normas, e articular ideias em prol de mudanças, pois tais coletivos poderiam representar, a curto ou longo prazo, fissuras, rachaduras, furos, brechas, estranhamentos e ameaças ao que está fixado como regra dominante nesses contextos.

No alto de sua visão gestionária, as forças hegemônicas envolvidas nesse ambiente laboral procuram abafar resistências, cimentar terrenos de solo fértil por onde poderiam florescer potentes compartilhamentos capazes de gerar transformações em prol da saúde dos sujeitos que nela trabalham. Durante a pesquisa, os sujeitos entrevistados relataram que durante alguns meses puderam participar de rodas de conversa com a temática da terceirização promovidas por estudantes e alguns professores, nas quais era possível expor suas angústias e compartilhar ensejos. De acordo com eles, a iniciativa se dissolveu por conta da indisponibilidade de espaços físicos nos quais os encontros pudessem acontecer.

Cabe reforçar, aqui, que a cooperação não pode ser dissociada das noções de identidade e saúde mental no trabalho que, por sua vez, são diretamente influenciadas pelas dinâmicas de reconhecimento que permitem, de maneira significativa, a obtenção de prazer no trabalho por meio das retribuições simbólicas sobre o fazer de cada sujeito (Moraes \& Vasconcelos, 2013). Nessa perspectiva, o reconhecimento se dá quando o fazer do trabalhador se torna visível aos olhos dos outros, ou seja, quando o seu trabalho se torna inteligível para outrem, pois quem é reconhecido tende a se sentir como parte de um coletivo, em meio às relações de cooperação Essa seria, por assim afirmar, a modalidade de socialização do reconhecimento e da cooperação (Dejours, 2004).

A questão que nos preocupa, aqui, é a impossibilidade de cooperação que se faz presente na dinâmica dos sujeitos subcontratados da universidade. Algo não pode ser reconhecido sem previamente tornar-se inteligível a outrem. Se não há veredas para que espaços vivos de trocas e de compartilhamento se constituam, não há, também, a possibilidade de enxergar o fazer do outro e, por conseguinte, de refletir sobre o seu próprio fazer.

\section{Feixe 2: A instituição dos instituídos e a naturalização de processos mortificantes}

Muitos são os funcionários cansados que trazem consigo as angústias relatadas no poema de António Ramos Rosa, significativo poeta português: "A minha alma não acompanha a minha mão [...] Sou um funcionário cansado de um dia exemplar. Por que não me sinto orgulhoso de ter cumprido o meu dever?" (Rosa, 1974, p. 10).

Em virtude mesmo dos múltiplos atravessamentos de ordem organizacional, institucional e política de seus contextos, as formas de trabalho dos sujeitos subcontratados se veem, no limite, reduzidas ao que Ferreira (2014) denominou de trabalho morto, ou seja, a uma conjuntura na qual suas capacidades inventivas são subtraídas e os sujeitos se veem abafados na lógica fechada das vivências de negação da potência viva do real.

Nesse curso de pensamento, e em meio ao crescimento do individualismo e ao aumento das formas precárias de trabalho e de vida, os sujeitos se veem cada vez mais isolados, sentindo-se solitários e recolhidos aos seus próprios sofrimentos (Dejours, 2007b). Sabemos, assim, que a impossibilidade de conhecer o sofrimento do outro impede que os sujeitos elaborem o seu próprio sofrimento e que se sintam parte de um coletivo. Este, em última instância, pode representar um importante elemento de resistência e luta frente às cristalizações que solidificam estes pesares em detrimento das possibilidades de ações instituintes de afirmação da vida, que levem em conta singularidades, potências, compartilhamentos e desejos.

Neste feixe de análise serão observados os riscos de sofrimento, as estratégias defensivas individuais e coletivas e outros elementos, observados durante as entrevistas, que podem encaminhar os subcontratados a horizontes contrários ao prazer no trabalho. No decorrer da nossa pesquisa, refletimos sobre como este movimento provoca o que chamamos de uma certa instituição do que está instituído, ou seja, um fortalecimento, uma solidificação, uma fermentação e fixação de prescritos limitantes em detrimento das inúmeras possibilidades vivas do real.

Eu queria até se eu pudesse, né... passar para cidadão, funcionário da UFRJ, mas isso aí ainda tá longe ainda, né, porque enquanto não acabar os terceirizados aqui não pode fazer isso [...] A gente pega de 8 às 17h, acho que está tudo beleza [...] isso aí é normal. (Ana Paula - participante da pesquisa)

Pra mim aqui em virtude de onde eu estava, não tem nem comparação, né. Eu trabalhava numa obra, debaixo de sol, carregando concreto [...]. Pra mim é bem melhor aqui do que onde que eu estava. (Sergio - participante da pesquisa)

A negação do real do trabalho conduz os sujeitos a negarem, também, o seu sofrimento. Assim, negar o real é supervalorizar os procedimentos, a organização (Dejours, 2007a). Esse movimento é revelado, mais claramente, a partir do agravamento do sofrimento psíquico nas situações de trabalho, muito influenciado pelo processo que Lhuilier (2012) denominou de uma crescente invisibilidade do trabalho real.

Em meio a dogmas produtivistas que tornam o cotidiano de trabalho extremamente precarizado estão, também, ideologias individuais e coletivas que reafirmam a naturalidade desta dinâmica. Percebe-se, principalmente em situações de terceirização, que impera uma certa perda de sensibilidade por parte dos sujeitos para com aspectos do trabalho que claramente evidenciam situações de desrespeito, submissão extrema, indignidade e perda de direitos (Druck, 2011).

Mas, tendo em vista esse contexto, pensemos em conjunto: como pode um subcontratado subverter tamanha dominação em seu ambiente de trabalho? De que maneira esse sujeito pode pensar em mudanças (em níveis individual e coletivo) em prol de seu bem estar se os seus benefícios básicos podem se ver ameaçados por sua conduta? Haveria a possibilidade de reclamar e reivindicar direitos elementares sob uma constante ameaça de demissão? Não seria mais fácil optar por uma negação das más condições de trabalho para que, pelo menos, o seu emprego e a sua pouca remuneração fossem minimamente garantidos?

O convite para esta reflexão já pressupõe a não obviedade de suas possiveis respostas. Compreendemos que as adversidades são de tantas origens, intensidades e sortes que, muitas vezes, as possibilidades de enfrentamento e mudança das mesmas parecem cenários muito distantes e que, neste movimento, as estratégias defensivas de negação da realidade apresentam-se como o caminho mais curto para sobreviver trabalhando. Com isso, não há estranhamento ou incômodo aparente frente ao que consideramos ser da ordem do desumano.

Nesse aspecto, devemos ter a consciência de que o medo também pode funcionar como o motor da inteligência no trabalho 
(Dejours, 2007a). A partir das entrevistas, há indícios de que os sujeitos em condição de subcontratação empregam sua personalidade, inteligência e subjetividade nas suas atividades cotidianas muito menos porque são reconhecidos por seu pares ou chefia do que pelo medo que sentem diante da possibilidade de demissão e perda de vínculo empregatício. Percebemos, portanto, que esses sujeitos continuam a trabalhar menos pelo prazer obtido nas atividades que realizam do que pelo medo de serem demitidos.

Nossas reflexões produzem ressonâncias com as contribuições de Dejours (2012) quando este autor afirma que os riscos no trabalho produzem o medo e que este último resulta na cooperação defensiva, em estratégias de defesa coletivas e em ideologias defensivas no contexto trabalhista. Assim, os medos geram conflitos intrapsíquicos que demandam a elaboração e a implementação de estratégias de defesa para conter o sofrimento psíquico. Dejours (2007a) ainda comenta que tais estratégias atenuam o sofrimento sem proporcionar a cura dos sujeitos, assim como freiam a emancipação desses sujeitos e a mudança de suas condições de trabalho.

As estratégias de defesa ajudam a manter as situações de trabaIho que elas mesmo deveriam combater, assim como os seus efeitos subjetivos. Dejours (2012) afirma que tais estratégias limitam os poderes do pensamento, são propulsoras subjetivas da servidão e da dominação e podem contribuir para a formação da violência. Essas estratégias também têm um caráter estruturante no que tange às possibilidades dos sujeitos pois representam, para além de seus aspectos negativos, modos de enfrentamento frente ao sofrimento experimentado no trabalho, sendo, portanto, as formas encontradas pelos sujeitos para se estruturarem - e garantirem a continuidade do seu fazer.

É de capital importância considerarmos que essas estratégias têm como base uma certa negação da percepção de realidade por parte dos sujeitos. Fazendo uso delas os sujeitos podem continuar trabalhando, embora ainda existam condições adversas que representam uma ameaça para a sua saúde psíquica. A espinha dorsal de todas as defesas centra-se no pensamento, na eufemização da percepção do risco, ou seja, no fazer de tal maneira que não se pense no que funda uma ameaça para a coesão psíquica (Dejours, 2012).

Ora, se percebemos que os subcontratados utilizam estratégias defensivas para enfrentar suas adversidades diárias, entendemos que esses sujeitos tendem a negar a sua percepção da realidade de trabalho, tentando não pensar nos riscos presentes neste contexto que possam acarretar mais sofrimento e problemas para a sua saúde. Observamos, assim, que a negação desse espectro leva a uma racionalização e uma naturalização do que está instituído na organização do trabalho como regra, ou seja, a um não estranhamento (por parte dos trabalhadores e trabalhadoras) das práticas normativas de submissão, humilhação e injustiça. Essa questão coloca em movimento o fato de que os sujeitos, cada vez mais, aceitam condições desumanas de trabalho pelo simples fato de estarem empregados, vinculados, mesmo que precária e sutilmente, a uma instituição empregadora.

Percebemos que, nessas situações, as formas flexíveis de trabaIho, que deveriam ser combatidas e transformadas, deixam de ser exceção para se tornarem regras. Desenha-se, assim, um quadro cíclico de manutenção de regras e formatos, visto que os sujeitos estão em constante processo de negação do que os incomoda e os faz sofrer e, por conta disso, as suas capacidades de se mobilizar ficam significativamente dificultadas. A manutenção das formas instituídas de trabalhar faz com que a potência do trabalho vivo seja circunscrita dentro dos limites de mecanismos de controle que delimitam um restrito campo de possíveis.
O maior efeito é quando atinge a minha família, como eu fiquei esses cinco meses sem salário, aquilo ali foi o que me deixou muito triste [...]. Tem um amigo meu que foi despejado, que desmaiou por estresse, teve pessoa que ficou desempregada, teve pessoa que ficou com o nome sujo no SPC. (Sergio - participante da pesquisa)

Mas como nós precisamos trabalhar, muitos por conta das condições de vida, né, escolaridade e outras coisas mais, então nós acabamos aceitando isso. (Letícia - participante da pesquisa)

No decorrer das entrevistas, percebemos que o número de subcontratados afastados do trabalho era bastante considerável. As razões para tal situação, segundo os próprios trabalhadores e trabalhadoras, seriam múltiplos problemas ocorridos no ambiente de trabalho - como desmaios e picos elevados de estresse -, falta de dinheiro para custear a locomoção por meio de transporte público de seus lares até a universidade e necessidade de resolver algumas urgentes questões extralaborais no horário do expediente, como ordens de despejo, pagamento de aluguel atrasado e solicitação de empréstimo junto a bancos.

Nesse sentido, tais situações corroboram a ideia de que a terceirização e as práticas precárias que a solidificam representam um dispositivo que fragmenta e influencia a diminuição da potência dos movimentos de resistência e transformação dos contextos de trabalho. Hamraoui (2014) afirma que o sofrimento é um aspecto fundamental nas relações laborais, representando uma origem e um ponto de partida para outros processos e ações. Porém, devemos atentar para o fato de que, caso ele seja vinculado à manutenção das vivências de fracasso nesses ambientes, pode desviar de sua rota criativa e abrir caminho para quadros de embotamento subjetivo e, em casos mais graves, de doença mental.

Num movimento cíclico, esses sujeitos veem-se atravessados por processos que coexistem e corroboram para o esmagamento de formas de trabalho dignas: eles não se veem reconhecidos pelo trabalho que realizam, o que aponta para problemas referentes à sua construção identitária, à atribuição de sentido ao seu fazer e à obtenção de prazer no trabalho; não têm abertura para compartilhar suas angústias e queixas coletivamente, o que impossibilita a cooperação e faz com que eles se vejam reconduzidos aos seus próprios sofrimentos; não recebem os seus benefícios básicos, o que gera problemas particulares de ordem familiar e econômica e preocupações constantes; e não são capazes, fundamentalmente, de engajar-se por completo em suas atividades, de modo que o seu saber-fazer, o seu trabalhar efetivo, fica obstruído pelos entraves dos moldes e formatações do seu contexto de trabalho.

\section{Feixe 3: Fissuras que apontam para outros horizontes}

"Ah, que ninguém me dê piedosas intenções, ninguém me peça definições! Ninguém me diga: "Vem por aqui»! A minha vida é um vendaval que se soltou, é uma onda que se alevantou, é um átomo a mais que se animou. Não sei por onde vou, não sei para onde vou. Sei que não vou por aí!" (Régio, 1984, p. 21).

Os versos do poema Cântico Negro, do escritor e poeta português José Régio, abrem passagem para reflexões acerca de possibilidades abafadas pelas imperativas formas prescritivas de trabalho na contemporaneidade. Eles apontam para uma realidade que os trabalhadores e trabalhadoras escolhem não aceitar e, a partir disso, optar pelo desbravamento de imprevisibilidades criativas e pela constituição de outras possíveis veredas.

Quais seriam, então, as maneiras de desmanchar e derreter as formas cristalizadas dos pilares do processo de terceirização? Como adicionar doses de porosidade nessa realidade tão fixada para que 
mudanças a favor de uma vida digna possam se engendrar? De que modo alguns subcontratados resistem à ofensiva das prescrições e iniciam movimentos de resistência em prol de transformações? Como resistir para (re)existir?

Mas os alunos que estão aqui para mim é uma satisfação, eu fazendo o meu trabalho e ver eles amanhã e depois formados, sabendo que eu contribuí de alguma forma [...]. É a primeira gestão que senta com a gente para conversar, entendeu? (Sergio - participante da pesquisa)

Em virtude mesmo dos tamanhos impasses que permeiam suas rotinas de trabalho, os subcontratados ainda conseguem enxergar e criar frestas de caráter satisfatório em seus cotidianos. Durante as entrevistas, percebemos que a fonte de tais sentimentos advém, principalmente, da relação desses sujeitos com os estudantes da instituição.

Em contrapartida, durante as entrevistas alguns participantes relataram que recentemente tem ocorrido um movimento de maior aproximação por parte de algumas instâncias da universidade com relação às demandas da classe de trabalhadores e trabalhadoras subcontratados. Aqui, podemos emergir uma reflexão que entende esse processo como algo que é sentido por esses sujeitos como uma certa retribuição, um certo tipo de reconhecimento proveniente da instituição. Poderíamos denominá-lo, aqui, de reconhecimento institucional. Tal abertura, ainda que insuficiente em seu caráter embrionário, traz uma espécie de alívio e esperança para os subcontratados, representando portas que podem conduzi-los a possibilidades de emancipação em meio às suas condições extremamente deficitárias de trabalho.

É sabido que, ao se deparar com uma retribuição simbólica pelo seu fazer, o sujeito constrói gradativa e processualmente sua identidade e passa a atribuir sentido ao seu trabalho. Em contrapartida, se não há reconhecimento, esse fluxo não se engendra e o sujeito se vê reconduzido ao seu sofrimento, situação que abre espaço para quadros de doença mental (Dejours, 2012). Uma vez que este trabalhar encontra espaço de escoamento para sua potência criativa, o sujeito pode mobilizar-se subjetivamente de modo que possa se engajar no seu fazer, expandir sua subjetividade e utilizar-se da sua inteligência prática no seio dos coletivos de trabalho. Aqui, devemos lembrar que essa dinâmica é viabilizada justamente pelas diversas formas de cooperação, retribuição e reconhecimento.

É de capital importância percebermos, também, que essa última noção tem suas limitações no que diz respeito ao seu papel no processo que envolve experiências de prazer nas situações de trabalho. Devemos ter a consciência de que o reconhecimento pode, inclusive, tomar um sentido contrário ao da promoção de autonomia e funcionar à serviço da banalização do mal e da manutenção dos instituídos nos contextos laborais (Dejours, 2007a). Essa espécie de reconhecimento-alçapão, assim denominado por Dejours (2012), está atrelada à dependência dos sujeitos com relação à organização do trabalho e, em outras palavras, dissimula o medo da solidão, a servidão voluntária e o oportunismo, fazendo com que a cooperação fique à serviço da participação de práticas injustas e discriminatórias.

Ferreira (2011) defende que o sofrimento criativo induz à criação e produz mobilização subjetiva para a transformação do sujeito e do mundo. A partir das entrevistas realizadas podemos observar que os trabalhadores e trabalhadoras, diante das ofensivas dos campos normativos com os quais estão diariamente em contato, formaram entre si um belo exemplo de resistência: a Associação de Trabalhadores Terceirizados da UFRJ (ATTUFRJ).
Tal qual uma flor que insiste em nascer em um local infértil e não propício, essa associação foi formada e é mantida pelos próprios subcontratados da universidade e possui como principal objetivo uma maior representatividade para as questões inerentes a sua classe trabalhista. Apesar das dificuldades encontradas na manutenção da iniciativa, esse potente núcleo já mobilizou diversas instâncias da instituição, assim como das empresas terceirizadas às quais os subcontratados estão vinculados e, como consequência, já conseguiu melhorias significativas, como o pagamento de salários que estavam atrasados e a concessão de oportunidades - por parte da instituição - para a promoção de espaços de discussão sobre terceirização.

Nós ficamos cinco meses sem salário e nesses cinco meses nós viemos trabalhar. (Renan - participante da pesquisa)

O nosso pagamento, como nós já fizemos, já vai sair até agora o pagamento atrasado que foi do ano passado que não pagaram né, parece que vão pagar agora em maio [...]. Porque na verdade nós temos um sindicato, mas esse sindicato é pelego, ele não faz nada pela gente... Então se ele não faz nada, nós estamos nessa luta. (Neuza - participante da pesquisa)

Então essas coisas todas deixa a gente muito triste. Tanto é que resolvemos criar a associação [...] pra ver se a gente consegue mudar esse quadro. (Renan - participante da pesquisa)

A flexibilização exacerbada, o descaso por parte das empresas contratantes com a qualidade dos serviços, a crescente pulverização e ausência de sindicatos da classe, somadas às negligentes condições de segurança e, principalmente, os atrasos nos pagamentos mensais foram elementos catalisadores do processo de articulação desses trabalhadores e trabalhadoras para a fundação da associação.

Em meio à ambígua relação de forças presentes, como o apoio aos subcontratados por determinados segmentos da universidade (servidores, professores e estudantes) e a forte resistência das empresas terceirizadas aos sujeitos organizados no movimento, a ATTUFRJ obteve conquistas importantes para sua classe, como o recebimento de salários atrasados, a diminuição da exploração e da carga horária de trabalho, campanhas de arrecadação de alimentos para os seus integrantes e maior aproximação nos diálogos com a Reitoria da instituição. Tais avanços reafirmam a potencialidade adormecida nas ações dos coletivos de trabalho diante da precarização naturalizada e banalizada das condições de trabalho dessa categoria.

Em paralelo à ATTUFRJ, destacam-se alguns outros movimentos coletivos de resistência no Brasil que se contrapõem à inexorabilidade do quadro atual da precarização do trabalho. Em meio à crise sindical, originada pela generalização de práticas degradadas de trabalho, o Sindicato dos Químicos e Petroleiros do Estado da Bahia formou um departamento próprio para trabalhadores e trabalhadoras terceirizados de empreiteiras da região, com o intuito de representá-los na organização cooperada em suas reivindicações por melhores salários e condições de trabalho. Ações coletivas mobilizadas pela classe de trabalhadores terceirizados foram observadas também durante a greve da Petrobras em 2009. A participação ativa desses sujeitos foi relevante na busca pela garantia dos seus direitos.

Com essa perspectiva, a construção de coletivos nos contextos de terceirização representa uma estratégia fundamental para a transformação do sofrimento e das adversidades no trabalho por 
meio de mobilizações conjuntas que visam mudanças trabalhistas e o reconhecimento de direitos dessa classe.

\section{Apontamentos finais}

No ensejo de promover uma reflexão crítica acerca da articulação entre a dinâmica da terceirização e processos de subjetivação observou-se, por meio do material aqui exposto sob a forma de feixes de análise, que os sujeitos envolvidos nesse contexto encontram-se em terceiro plano diante das prioridades capitalistas da conjuntura laboral contemporânea.

Em meio ao imperativo de formas hegemônicas de trabalho, sinalizadas durante as entrevistas, observamos que o surgimento de movimentos de resistência e enfrentamento representa uma certa materialização do potente incômodo desses sujeitos para com os limites instituídos que se sobrepõem à potência do seu fazer. Tomemos a título o exemplo da ATTUFRJ, germinada por meio da mobilização coletiva dos subcontratados que já resultou na reparação do descumprimento de direitos, principalmente no que se refere ao pagamento de salários atrasados.

Acredita-se que o material aqui reunido representa um instrumento que pode servir como aparato acadêmico para justificar ações em prol da saúde dos subcontratados da universidade. Nesse sentido, entendemos que a continuidade de produções acadêmicas relacionadas à temática da terceirização se faz cada vez mais necessária no seu intuito de iluminar importantes reflexões acerca dos efeitos desse processo, corroborando as reivindicações dos sujeitos nele envolvidos e trazendo maior legitimidade, atenção e destaque para suas questões nos âmbitos acadêmico, econômico e legislativo.

Por fim, acreditamos que, na dinâmica da terceirização, o que pode ser terceirizado não é o sujeito na complexidade do seu fazer singular. A questão que nos mobiliza aqui é pensar que não é - e não deve ser - possível terceirizar alguém, terceirizar um fazer próprio, terceirizar um trabalho que, de acordo com as contribuições do referencial teórico-metodológico aqui escolhido, representa o poder de sentir, pensar e inventar.

Percebemos que a naturalização de práticas instituídas e normativas promove um forte empuxo para que se acredite que seja possível subcontratar singularidades, afetos, experiências, incômodos, potências e desejos. O que defendemos aqui é que devemos integrar o esforço de não (re)produzir os aspectos normativos e identitários que nos conduzem, no limite, a uma terceirização da vida. A velocidade do fluxo do processo de subcontratação encontra um grande obstáculo em seu curso e é circunscrita pelos movimentos de resistência e de afirmação de formas de vida ética e politicamente referenciadas, no caminho para o encontro com imprevisibilidades de outros possíveis.

\section{Referências Bibliográficas}

Antunes, R. L. C., \& Druck, M. G. (2015). A terceirização sem limites: A precarização do trabalho como regra. O Social em Questão, 18(34), 19-40. Recuperado de http://osocialemquestao.ser.puc-rio.br/media/OSQ_34_1_Antunes_ Druck.pdf

Antunes, R. L. C. (2014). Desenhando a nova morfologia do trabalho no Brasil. Estudos Avançados [USP Impresso], 28(81), 39-53. doi: 10.1590/S01034014201400020000428

Barros, M. (1998). Retrato do artista quando coisa. Rio de Janeiro: Record.

Barros, P. C. R., \& Mendes, A. M. B. (2003). Sofrimento psíquico e estratégias defensivas dos operários terceirizados da construção civil. Psico-USF, 8(1), 63-70. doi: 10.1590/S1413-82712003000100009

CUT-DIEESE (2014). Terceirização e desenvolvimento: Uma conta que não fecha. In: Dossiê acerca do impacto da terceirização sobre os trabalhadores e propostas para garantir a igualdade de direitos. Secretaria Nacional de
Relações de Trabalho e Departamento Intersindical de Estatística e Estudos Socioeconômicos. São Paulo: Central Única dos Trabalhadores, 2014. Recuperado de: https://www.cut.org.br/system/uploads/ck/files/DossieTerceirizacao-e-Desenvolvimento.pdf

Dejours, C. (1999). A banalização da injustiça social. Editora FGV, Rio de Janeiro. Dejours, C. (2004). Subjetividade, trabalho e ação. Produção, 14(3), 27-34. doi: 10.1590/S0103-65132004000300004

Dejours, C. (2007a). Banalização da Injustiça Social. 7 Ed. Rio de Janeiro: Editora FGV.

Dejours, C. (2007b). A psicodinâmica do trabalho na pós modernidade. In: Mendes, A. M. B., \& Lima, S. C. C., \& Facas, E. P. (Orgs.). Diálogos em psicodinâmica do trabalho (13-26). Brasília: Paralelo 15.

Dejours, C. (2012). Trabalho vivo, tomo II, Trabalho e emancipação. Brasília: Paralelo 15.

Druck, M. G. (2013). A Precarização Social do Trabalho no Brasil: Alguns indicadores. In: Antunes, R. L. C. Riqueza e miséria do trabalho no Brasil II (55-73). São Paulo: Bomtempo Editorial.

Druck, M. G. (2011). Trabalho, Precarização e Resistências: Novos e velhos desafios?. Caderno CRH [UFBA. Impresso], 24(1), 35-54. doi: 10.1590/ S0103-49792011000400004

Ferreira, J. B. O. (2011). Do Poema Nasce o Poeta: Citação literária, trabalho e subjetivação. Rio de Janeiro: 7Letras.

Ferreira, J. B. O. (2014). Sobrevivências, Clandestinidades e Lampejos: O Trabalho Vivo da Criação Literária. Fractal, Rev. Psicol., 26(n. esp.,) p. 715-728. doi: 10.1590/1984-0292/1322

Ferreira, J. B. O., Martins, S. R., \& Vieira, F. O. (2016). Trabalho vivo como apropriação do inapropriável e criação de formas de vida. Trabalho (En)Cena, 1(1), 29-49. Recuperado de https://sistemas.uft.edu.br/periodicos/index.php/ encena/article/view/2336

Relatório de Acidentes de Trabalho da Fundação COGE - Comitê Gestor Empresarial. (2013). Recuperado de http://www.funcoge.org.br/csst/ relat2013/

Filgueiras, V. A. (2014). Terceirização e trabalho análogo ao escravo: Coincidência?. Repórter Brasil. Recuperado de https://indicadoresdeemprego.files.wordpress.com/2013/12/tercerizac3a7c3a3o-e-trabalho-anc3a1logo-ao-escravo1.pdf

Filgueiras, V. A., \& Druck, M. G. (2014). A epidemia da terceirização e a responsabilidade do STF. Revista do Tribunal Superior do Trabalho, 80(3), 106-125. Recuperado de https://juslaboris.tst.jus.br/bitstream/handle/1939/71131/006_druck_filgueiras.pdf?sequence=1\&isAllowed $=y$

Filgueiras, V. A., \& Cavalcante, S. M. (2015). Terceirização: Debate conceitual e conjuntura política. Revista da ABET [Impresso], 14(1), 15-36. Recuperado de http://periodicos.ufpb.br/ojs/index.php/abet/article/view/25699/13875

Filgueiras, V. A., \& Dutra, R. Q. (2014). O Supremo e a repercussão geral no caso da terceirização de atividade-fim de empresas de telecomunicações: $O$ que está em jogo?. Revista Eletrônica - Tribunal Regional do Trabalho do Paraná, 4, 123-135. Recuperado de https://indicadoresdeemprego.files.wordpress. com/2013/12/o_supremo_e_a_repercussc3a3o_geral_no_caso_da_terceirizac3a7c3a3-o_de_atividade-fim_de_empresas_de_telecomunicac3a7c3b5es.pdf

Fonseca, T. M. G., Engelman, S., \& Giacomel, A. E. (2004). A emergência da economia imaterial e as mutações subjetivas contemporâneas. In: Merlo, A. R. C (Org.). Saúde e trabalho no Rio Grande do Sul. Porto Alegre: UFRGS.

Hamraoui, E. (2014). Souffrance au travail, politiques de santé publique, management humaniste et évaluation: La vie pour enjeu de questionnement. In: Mendes, A. M. B., Moraes, R. D., \& Merlo, A. R. C. (Orgs.) Trabalho e sofrimento. Práticas clínicas e políticas (115-138). Curitiba: Juruá.

Lima, J. C. (2010). A terceirização e os trabalhadores: Revisitando algumas questões. Cadernos de Psicologia Social do Trabalho (USP), 13(1), 17-26. Recuperado de http://pepsic.bvsalud.org/scielo.php?script=sci_arttext\&pid $=$ S1516-37172010000100003

Lhullier, D. (2012). A invisibilidade do trabalho real e a opacidade das relações saúde-trabalho. Revista Trabalho \& Educação, 21(1), 13-38. Recuperado de http://www.portal.fae.ufmg.br/seer/index.php/trabedu/article/ view/991/854

Mendes, A. M. B. (Org.) (2007). Psicodinâmica do trabalho: Teoria, método e pesquisas. São Paulo: Casa do Psicólogo.

Moraes, R. D., \& Vasconcelos, A. C. L. (2013). A subversão do sofrimento em prazer no trabalho. In: Schlinwein, V. L. D. C. (Org.). Saúde mental e trabalho na Amazônia: Múltiplas leituras sobre prazer e sofrimento no trabalho, 1, 51-59. Recuperado de http://www.edufro.unir.br/submenu_arquivos/688_saude_mental_e_trabalho_na_amazonia_vanderleia.pdf

Pujol, A. (2015). Trabajo creativo, subjetividad y posibilidades del abordaje clínico. Trabajo y Subjetividad. Indagaciones clínicas. Simposio TAS 2014 
- Universidad Nacional de Córdoba, E-book, 23-32. Recuperado de http:// www.simposiotas.com.ar/Libro_TAS.pdf

Régio, J. (1984). Poemas de Deus e do Diabo. Vila Nova de Famalicão: Quasi Edições.

Rosa, A. R. (1974). Não posso adiar o coração. Lisboa: Plátano. 